${ }^{I}$ Casa de Oswaldo Cruz, Fundação Oswaldo Cruz, Rio de

Janeiro, Brasil

alejandra.josiowicz@gmail.com

Alejandra Josiowicz'

\title{
POR UMA POLÍTICA DA ESTÉTICA EM MÁRIO DE ANDRADE: EXPRESSIONISMO E INFÂNCIA
}

Este artigo propõe considerar a cena da infância ${ }^{\mathrm{I}}$ em Mário de Andrade a partir de dois níveis ou esferas de atuação distintos: por um lado, em sua intervenção político-cultural e, por outro, em sua produção literária. Em ambos os níveis, examina-se em Mário de Andrade uma "política da estética": uma conjunção de preocupações sociais e raciais, interesses etnográficos e reflexões estéticas em torno da infância. ${ }^{2}$ Em primeiro lugar, no nível de sua atuação político-cultural, Mário de Andrade se relaciona com os reformadores sociais de seu tempo, os quais pensaram a criança como receptora de políticas médicas, sociais ou jurídicas, e como núcleo da formação da cultura brasileira. Ao mesmo tempo, se diferencia de outros artistas e escritores de vanguarda porque, dadas as suas investigações de etnografia e de arte infantil, concebe a expressão estética da criança não de modo puramente pulsional, transgressor e inconsciente, mas como um artista expressionista, que intervém nas leis da representação através de uma força poético-mítica própria, a partir da qual seria capaz de criar uma arte brasileira futura. Em segundo lugar, no nível de sua produção literária, Mário de Andrade faz da cena de infância e adolescência um modo de intervenção na linguagem estética e na hermenêutica do social: o infantil implica a incorporação de temas e linguagens populares e de outros considerados banais ou vulgares e, por sua vez, aponta para as hierarquias raciais, sociais e de gênero que estruturam o social. Em seus múltiplos níveis estético-políticos, a infância em Mário de Andrade revela a marca do excluído e se orienta à transformação das hierarquias estéticas e da representação. 
"Piá não sofre? Sofre" - relato que Mário de Andrade publica primeiro em I926 e reelabora em I 944 como parte da seleção que intitula Os contos de Belazarte $e^{3}$ conta a história de Paulino, criança de quatro anos, filho de um mulato e de uma imigrante italiana, que vive em um bairro industrial da periferia de São Paulo. Preso seu pai, sua mãe, lavadeira, sem dinheiro, o entrega à avó paterna, que não consegue dissuadi-lo do vício adquirido: comer terra, o que o deixa cada vez mais doente e o "aniquila". Numa tarde, sentado na calçada vendo passar os operários que saíam da fábrica, reconhece sua mãe, vestida com elegância, maquilada e penteada, e a chama, exaltado: "Mamma!". A mãe corre para abraçá-lo e chora: a imagem do filho, negligenciado e doente, a faz titubear - deixá-lo novamente com a avó ou levá-lo consigo -, mas se convence de que seria impossível continuar com a vida que leva, que seu filho está bem como está e decide ir embora, "para não pensar nele nunca mais". Dá-lhe um beijo na boca cheia de muco por causa do catarro, "Figliouolo", diz a ele, e parte. Paulino a vê desaparecer na distância, sentado no degrau da calçada: "As cores da tarde iam cinzando mansas. Paulino encostou a bochecha na palminha da mão e meio enxergando, meio escutando, numa indiferença exausta, ficou assim. Até a gosma escorria da boca aberta na mão dele. E depois pingava na camisolinha. Que era escura para não sujar" (Andrade, 2008b: I I4). A figura da criança doente, sentada sozinha, olhando o horizonte com ar ausente, pensativo, consequência do abandono moral e material da mãe prostituída, quero propor, revela o dilema estético-político da representação, a "política da estética" em Mário de Andrade. A citação mostra Paulino em um plano ampliado, cinematográfico, apoiando a bochecha na mão, no crepúsculo do bairro industrial paulista. O conto, poder-se-ia pensar, funciona como uma ferramenta de visibilizacão daquilo que ficou fora de foco, excluído do laço social. O conto viria a ser uma reparação simbólica do abandono que sofre a criança, denúncia e impugnação do desamparo por parte da mãe, que se convence de que está bem como está e decide partir para não pensar nele nunca mais. No entanto, o foco final na saliva mucosa ("gosma"), caindo primeiro sobre a mão de Paulino e depois sobre a camisolinha, revela que existe um nível de análise adicional. O líquido é um sintoma de seu padecimento - produto da tosse que o vem aniquilando lentamente, tal como o tifo que matou seu irmão pequeno -, mas o catarro cai sobre a roupa de Paulino sem deixar marcas, dada a opacidade da superfície da camisola, intencionalmente escura "para não sujar". Ao assinalar a intenção de ocultar o sintoma, o texto ressalta sua "política da estética": não se trata simplesmente de visibilizar um referencial excluído, mas sim, mais radicalmente, de intervir na partilha mesma do sensível, na relação entre o percebido e o dito, e nas interpretações do social. "Piá não sofre? Sofre" faz da criança pobre não um referencial passivo, mas um modo de reconfigurar as 
formas de perceber e experimentar o social, politizando ao mesmo tempo o visível, sua visibilidade e os próprios sujeitos participantes destes processos.

Se Peter Bürger já havia sugerido que a obra de arte vanguardista, definida por sua não organicidade, se propunha devolver à experiência estética sua função social, superando assim a dicotomia entre arte pura, autônoma, e arte política (Bürger, I984: 9I), o conceito de "política da estética", do teórico Jacques Rancière, leva estas elaborações ainda mais além. A "política da estética", segundo Rancière, implica a intervenção da estética na "partilha do sensível": no recorte dos tempos e dos espaços, do visível e do invisível, do falado e do escrito (Rancière, 20I I). Trata-se de uma reconfiguração da experiência e da hermenêutica do corpo social, que consiste no enfrentamento de um novo regime de expressão - que desestabiliza a hierarquia entre linguagens nobres e baixas - e um princípio democrático que considera a promoção social e política dos seres "ordinários". Essa democratização ao mesmo tempo política e estética determina a ruptura da relação hierárquica entre formas e conteúdos, e inaugura "uma nova relação entre o ato da palavra, o mundo que este configura e as capacidades daqueles que povoam esse mundo" (Rancière, 20I I: 29). Desse modo, delimita o sentido mesmo da comunidade, as formas de sua visibilidade e de sua organização, revelando quem pode participar do comum (Rancière, 2006).

Porém, são os debates e elaborações ao redor do expressionismo ${ }^{4}$ que permitem dar conta do sentido da "política da estética" em Mário de Andrade. Em um debate sobre o expressionismo que mantiveram, por volta de I938, na revista Das Wort, Marc Bloch, Georg Lukács e Bertold Brecht, os teóricos discutiram a relação entre vanguarda, realismo e crítica social, isto é, o papel histórico da vanguarda na modernidade. Enquanto Lukács denuncia o expressionismo por sua "estética decadente" - uso não referencial e puramente expressivo das palavras, perspectiva subjetivista microscópica, uso "atávico" do folclore, demolição do real, caos e montagem - que resultaria em uma mistificação da realidade, parasitária da ideologia burguesa (Bloch et al., 2002), Bloch o defende como um modo de conciliar o substrato popular, folclórico - da arte "bárbara" das crianças, dos presos, dos doentes mentais e dos analfabetos - com a elaboração formal da arte moderna (Bloch et al., 2002). Nesses mesmos anos, Brecht também recupera o legado do expressionismo como resolução do dilema entre arte experimental de vanguarda e arte popular, conectado com as massas e aliado do realismo (Bloch et al., 2002).

Atraído pelo idioma alemão, assim como por suas leituras de revistas como Der Sturm (I924-I924) ou da francesa Europe (I923-I929) e por antologias literárias, Mário de Andrade se interessou pelo expressionismo (Mello e Souza, I980: 265), em relação com as discussões sobre o realismo e a busca de uma nova expressividade estética. ${ }^{5}$ No artigo "Questões de arte", afirma que para evitar os vícios de uma arte institucionalizada, intelectual e individualista, o 
expressionismo deve partir de um realismo "deformado" - não orgânico -, assim como de uma exploração do "elemento social", "popular", para recuperar força expressiva e conseguir uma "sensorialidade mais legitimamente plástica" (Andrade, I995: 386). Na mesma direção, no artigo "Oswald de Andrade: Pau Brasil, sans pareil, Paris, I925", afirma: "Dadá é niilista e abandona a realidade pela imagem. Expressionismo é universalista e gigantiza a realidade pela deformação. Pau Brasil é nacionalizante e realista, une a imagem à realidade tornando aquela compreensível e sem deformar expressionistamente esta" (Andrade, 2003: 79). Se a estética realista de Pau Brasil une a imagem à realidade sem deformá-la, resultando em uma estética intelectual, compreensível, "nacionalizada", o expressionismo agudiza a relação com o real, a intensifica, através de uma estética deformada e universal.

Por outro lado, como afirmou Alfredo Bosi, o expressionismo representa, em Mário de Andrade, um modo de transcender a rigidez dos gêneros: o realismo positivista, infestado de clichês, com sua psicologia de tipos, ou o regionalismo romanesco da República Velha e a retórica neoparnasiana (Bosi, 2003). Fundamentalmente, tal como argumentou Telê Porto Ancona Lopez, o expressionismo implica a união do sentido estético com a crítica social: proporciona uma estética do periférico, voltada para o imigrante, o operário, as vidas minguadas ou medíocres, o analfabeto, o marginal e a criança, aqueles que descobrem em sua condição de "eterno inconsciente" uma visão "inocentemente poética do drama social do Brasil popular" (Lopez, I996: 32).

Inspirado por um artigo de arte expressionista que lê em I9I9 em Deutch Kunst und Dekoration onde aparecem reproduções de arte infantil (Lopez, I988) e por seu interesse na bibliografia teórica sobre o desenvolvimento do sentido plástico das crianças - lê Georges Rouma, Le langage graphique de l'enfant (I9I3), e Georges Luquet, Le dessin enfantin (I927) e L'art primitif (I930) -, Mário de Andrade investigou o expressionismo da visão estética da criança. Além disso, como parte de sua investigação etnográfica mais ampla, se interessou pela cultura popular oral infantil: compilou, recebeu de outros e cotejou com suas próprias memórias canções de ninar e cantigas provenientes do Norte, Minas Gerais, São Paulo, e Rio Grande do Norte, assim como outras de origem portuguesa. ${ }^{6}$ Dada sua conjunção de uma perspectiva estética com uma social e etnográfica, Mário de Andrade dialogou, ainda que sem nomear diretamente seus interlocutores, tanto com os outros escritores do modernismo brasileiro que experimentaram com uma estética infantil, como com os médicos, psiquiatras, juristas e outros reformadores sociais que se preocuparam com a infância como realidade social do Brasil daquelas décadas.

Oswald de Andrade, como afirmou Haroldo de Campos, propôs "uma espécie de jardim de infância da expressão" (Campos, I98I: I I), e em seu Primeiro caderno do aluno de poesia Oswald de Andrade, de I927 - cuja capa é um desenho naïf que representa diferentes estados do Brasil feito por Tarsila do 
Amaral - simulou a caneta desajeitada, tartamuda e lúdica da criança, para construir uma sátira da geografia política e da história nacional brasileiras. A criança-aluna enunciadora de Oswald de Andrade transgride normas escolares e cânones literários, satiriza os símbolos pátrios e põe em cena - através do rabisco, da oralidade dialetal da linguagem imigrante e do erro ortográfico - a experimentação com a infância como signo do lúdico, do inconsciente e do anárquico (Antelo, I99I). Por sua vez, Flávio de Carvalho, como membro do CAM (Clube dos Artistas Modernos), organiza em I933 a "Semana dos loucos e das crianças", que chama a atenção do meio artístico e cultural de São Paulo para a relação entre arte moderna, crianças e sujeitos alienados. Diz Flávio de Carvalho:

Os verdadeiramente grandes artistas se parecem com as crianças nas suas invenções, possuem uma espontaneidade inconsciente em cor e forma, sem a preocupação dos trucs dos prestidigitadores das escolas de belas artes. A função dos professores de desenho e de escolas de belas artes tem sido quase sempre abafar ou matar qualquer surto de originalidade que aparece na fantasia da criança. Indivíduos quase sempre medíocres, estes professores gostam de impor a criança a sua personalidade gasta e empoeirada (Carvalho apud Coutinho, 2002: 29).

A criança aparece aqui como artista anárquico, inconsciente, espontâneo, alheio a toda educação técnica. Segundo Carvalho, o influxo da escola, dos docentes e dos cânones seria indefectivelmente repressor e daninho, restringindo a originalidade da criança, impondo clichês e estereótipos. Tanto Oswald de Andrade quanto Flávio de Carvalho se diferenciam da exploração da infância em Mário de Andrade, para quem a criança constituía não um princípio anárquico de espontaneidade, mas o depositário e partícipe da criação de uma nova cultura brasileira.

Por outro lado, desde a proclamação da República e do início do século XX no Brasil, a chamada "causa da salvação das crianças" do "abandono moral e material" se tornou parte de uma missão patriótica, de uma verdadeira cruzada empreendida por reformadores a partir da sociologia, da psicologia da psiquiatria e da antropologia, em busca das causas da criminalidade, do abandono e da mortalidade infanto-juvenil (Rizzini, 2002: 173). A partir da década de I920, com o surgimento do movimento da escola nova no Brasil e, mais tarde, com as políticas instituídas pelos governos de Getúlio Vargas, a categoria jurídica e penal da "menoridade" (na qual a criança pobre era estigmatizada, considerada uma ameaça para a ordem social) cedeu espaço a uma caracterização social que apostou na educabilidade da natureza infantil, abandonou as características deterministas da "anormalidade" e deu lugar a uma visão otimista da educação como regeneração de populações antes consideradas não aptas (Carvalho, I997). Esse processo foi acompanhado por um movimento mundial e hemisférico a favor dos direitos da criança: em resposta à Primeira Guerra Mundial e à depressão econômica mundial de I929, os países 
latino-americanos promulgaram seus Códigos de Menores - Brasil em I927, Uruguai em 1934, Argentina em I932 - e organizaram congressos nacionais, internacionais e interamericanos para a proteção da infância, nos quais se colocou uma ênfase específica nas responsabilidades dos Estados nos cuidados com as crianças (Guy, I998: 272). A centralidade da infância nos debates sobre a nacionalidade e a questão social a tornou objeto de interesse para um intelectual como Mário de Andrade que, no entanto, concebeu de modo particular e específico o papel da população infantil em uma cultura brasileira em gestação.

\section{II}

Para o grupo de intelectuais que atuaram no Departamento de Cultura e Recreação da Prefeitura de São Paulo entre I935 e I938, durante a gestão do Prefeito Fábio Prado, o desenvolvimento de políticas culturais, iniciativas artísticas e educacionais teve um lugar central.7 Como a crítica já assinalou, o Departamento de Cultura e Recreação de São Paulo, assim como a atuação do próprio Mário de Andrade nele, formaram parte de um processo mais amplo de reconfiguração de forças econômicas e políticas, tanto a nível nacional quanto estadual. ${ }^{8}$ Nesse cenário de radicais transformações político-sociais, esses intelectuais conceberam a política cultural como um modo de intervenção social e de formação da cidadania. Conscientes do caráter inovador do projeto de construção institucional, eles se apoiaram no aparato estatal como instrumento de mudança sociocultural.

Como Diretor do Departamento de Cultura e Chefe da Divisão de Expansão Cultural da Prefeitura de São Paulo, Mário de Andrade efetuou uma série de políticas públicas orientadas ao desenvolvimento artístico infantil e iniciou uma investigação etnográfica e sociológica das crianças paulistas. ${ }^{9}$ Os Parques Infantis, um dos programas no qual a presença de Mário de Andrade foi mais destacada, eram áreas de recreação instaladas na proximidade de fábricas, escolas ou bairros populares, onde as crianças filhas de operários levavam a cabo práticas esportivas, recebiam assistência médica, higiênica e nutricional, e participavam de eventos artísticos, exibições de cinema educativo, concertos, espetáculos e concursos de arte dramática. ${ }^{\text {Io }} \mathrm{Na}$ "Ata de Criação" dos Parques Infantis, enumera-se entre seus objetivos: "propagar a prática de brinquedos e jogos nacionais, cuja tradição as crianças já perderam ou tendem dia a dia a perder", "promover a prática de todos os jogos que, pela experiência universal, forem dignos de ser incorporados ao patrimônio dos jogos inspirados nas tradições locais e nacionais" e

promover, com a colaboração do corpo docente das instituições escolares municipais, estaduais e particulares, um inquérito permanente de pesquisas "folklóricas", e, mais geralmente, etnológicas, entre a população escolar, recolhendo assim 
as tradições de costumes, superstições, adivinhas, parlendas, histórias, canções, brinquedos etc., sendo os resultados desses inquéritos devidamente selecionados, organizados e catalogados em seções distintas, e publicados na Revista do Departamento (Andrade apud Faria, 2002: I39).

Trata-se de uma tríplice tarefa: em primeiro lugar, difundir entre as crianças a cultura popular nacional e regional que se considera perdida ou esquecida; em segundo lugar, incorporar as tradições "universais" trazidas pelos filhos de imigrantes; e, em terceiro, investigar, desde um ponto de vista etnográfico, as crianças como sujeitos portadores de cultura oral popular - de superstições, adivinhações, canções, jogos e histórias. A criança aqui aparece como um dinâmico portador de cultura, receptor, herdeiro e depositário cultural, que reatualiza um substrato cultural tradicional e é ao mesmo tempo portador e beneficiário da construção de uma nova cultura brasileira. ${ }^{\text {II }}$

Nessa direção, no discurso comemorativo do dia de fundação de São Paulo, Andrade afirma:

Nos jardins [de São Paulo] encontrareis recintos fechados com instrutoras, dentistas, educadoras sanitárias dentro. São os parques infantis onde as crianças proletárias se socializam aprendendo nos brinquedos o cooperativismo e a consciência do homem social. [...] As tradições ressurgem e com elas os costumes do passado. São crianças tartamudeando em torno duma Nau Catarineta de vime as melodias que seus país esqueceram, e nos vieram de novo da Paraíba, do Rio Grande do Norte e do Ceará (Andrade, I936b: 273).

Os Parques Infantis aparecem aqui, por um lado, como âmbito de preparação e formação dos sujeitos de uma ordem social futura e, por outro, como espaços de reatualização da cultura popular brasileira regional, encenada no corpo e na voz das crianças. Mário de Andrade se refere aqui à representação do bailado tradicional de origem portuguesa "A Nau Catarineta", realizada pelos filhos de imigrantes "italianos, espanhóis, russos, húngaros" do Parque Infantil Pedro II, por ocasião do I Congresso da Língua Nacional Cantada, para a qual se utilizou material folclórico pertencente ao acervo da Discoteca Pública, adaptado para a encenação infantil. O significativo do evento é que atualiza o papel da criança como receptora, portadora e sujeito da construção de uma cultura brasileira nova que incorpora a cultura urbana, cosmopolita e regional. Assim, fundamenta em uma entrevista para O Estado de S. Paulo:

Não será esse o mal maior do Brasil? Essa ausência de um "homem brasileiro", de um ser uno e coletivo que persista dentro de todos nós e reja a nossa unidade nacional? O Departamento não pode ficar indiferente a esse problema capital, que deve ser problema capital para todos os organismos oficiais do país. E o trabalho só pode ser feito na argila das crianças e dos moços. Bater no bronze duro é querer transformar Pinheiro Machado em Carlos Gomes. Mas infelizmente é $3 \mathrm{As}$ crianças e os jovens aparecem como depositários da possibilidade de construção de uma nova cultura brasileira, "argila" de criação de um "ser uno e coletivo" que 
oriente a unidade nacional. Dada a "ausência de um 'homem brasileiro'”, a criança se torna um núcleo fundamental da constituição de uma nova coletividade. A representação do bailado tradicional revela-se como um modo de reativar, de trazer ao presente, no corpo das crianças, a cultura brasileira regional popular e transformá-la em elemento ativo de construção cultural.

Como Diretor do Departamento de Cultura, Mário de Andrade também organizou um concurso de desenho entre as crianças frequentadoras dos Parques Infantis e da Biblioteca Municipal, dando orientações muito precisas às instrutoras de que não deveriam interferir com sugestões ou "muito menos" correções nos desenhos, e que deveriam evitar as cópias. ${ }^{12}$ Com os desenhos resultantes do concurso, somados a outros que compilou ou foram entregues por amigos, Andrade organizou uma verdadeira coleção de arte infantil com mais de 2.000 desenhos provenientes de todo o Brasil. ${ }^{13}$ Mais tarde, devido à reconfiguração do horizonte político posterior ao golpe de I937, teve que deixar seu posto no Departamento de Cultura e se mudou para o Rio de Janeiro, onde ofereceu um curso de Filosofia e História da Arte na recém-criada Universidade do Distrito federal (UDF), no marco do qual teorizou sobre a capacidade de expressividade plástica da criança, através de uma teoria de inspiração antropológica (filo e ontogenética) da arte, em paralelo e contraste com o primitivo. ${ }^{\mathrm{I4}}$

Nessas aulas, após um balanço da bibliografia teórica sobre o desenvolvimento das possibilidades artísticas da criança, Andrade refuta a teoria da espontaneidade e originalidade da arte infantil, dada a sua natureza "antitécnica", "ocasional”, "imitativa” e seu caráter rotineiro e repetitivo. Ainda que fosse sensível à contemplação estética, a criança não desenvolveria uma verdadeira capacidade artística até os 8 ou 9 anos de idade, quando a educação e imitação do adulto estimulam o desenvolvimento da técnica de reprodução realista. Se estas reflexões, de caráter psicológico e etnográfico, pareciam refutar toda relação entre arte moderna e desenho infantil, Andrade passa então a uma análise detida dos desenhos provenientes do concurso organizado por ele. Começa com uma comparação sociológica entre os desenhos feitos pelas crianças das diferentes camadas sociais da população paulista, a partir da qual reflete sobre a relação entre origem social e capacidade estética de expressão nos diferentes grupos. E, logo depois de descrever em detalhe suas características artísticas, afirma que a arte da criança deve ser pensada em relação com o expressionismo:

O expressionismo... expressivo é o domínio legítimo da arte desenhística infantil. O seu realismo é de natureza expressionista. É por este seu expressionismo de realização que o "realismo visual" da criança já artista persevera na realidade de um "idealismo", o que Luquet chamou de "realismo intelectual". A criança, mesmo artista, já obedecendo à perspectiva e outras leis do realismo visual, jamais copia a natureza. A sua tendência à imitação é sempre coada através de um sentimento lírico, ou milhor (sic), mítico, das coisas, antirrealista por essência, e que a tudo reveste de uma violenta e inocente poesia (Andrade, I966: 76). 
Este paralelo entre arte infantil e arte expressionista se funda no fato de que, inclusive na etapa de culminação da capacidade artística infantil - o "realismo visual", dado pelo uso da perspectiva e da intenção imitativa do real -, perseveraria na arte da criança um sentimento lírico, mítico, antirrealista. A arte da criança expressionista quebra as leis de um realismo orgânico ou reflexo, e agudiza o efeito do real através de uma perspectiva subjetivista, poética, mítica, dado que "a tudo reveste de uma violenta e inocente poesia".

Por outro lado, nas crônicas que escreveu para o Diário Nacional entre I927 e I932, Mário de Andrade, conhecedor de experiências como as "escolas ao ar livre" desenvolvidas no México por José Vasconcelos, ${ }^{15}$ orientou suas pesquisas estéticas em direção a suas preocupações sobre a cultura brasileira, refletindo sobre os meios pedagógicos mais adequados para estimular a expressão estética infantil (Andrade, I976). Assim, na crônica "Pintura Infantil", sobre uma exposição de pinturas infantis das turmas dirigidas por Anita Malfatti, ${ }^{16}$ sublinhou a importância da formação do sentido estético das crianças, concluindo que:

Mesmo que não atinjamos os resultados perfeitamente extraordinários do ensino plástico japonês ou das escolas ao ar-livre mexicanas, e não me parece impossível igualá-las, todo e qualquer ensino tendente a desenvolver a imaginação criadora tem de ser sistematizado muito entre nós. [...] Pouco me interessa a criação de gênios individuais. Mas tudo nos leva a sermos um povo de artistas (Andrade, I976: 279).

O desenvolvimento da "imaginação criadora" nas escolas de arte constituiria uma tarefa central para a constituição de uma cultura não de "gênios individuais", e sim de criadores coletivos, "povo de artistas". É neste sentido que se deve entender o expressionismo da arte da criança em Mário de Andrade: como uma conjunção de interesses estéticos, etnográficos e sociais, nos quais a infância aparece como eixo de uma renovação sociocultural.

\section{III}

Mário de Andrade também indagou a cena da infância em sua obra literária. Assim, o herói sem caráter de Macunaíma (I928), protagonista mítico, quase indígena, é uma versão monstruosa da criança: com sua "aura de espontaneidade polimorfa", Macunaíma nasce feio, se nega a falar até os seis anos, é grosseiro e pornográfico, tem constante apetite sexual e carece de todo sentido de responsabilidade e de coesão moral (Bosi, 2003: 202). Além disso, em seus relatos, a infância encena realidades muitas vezes opostas, mas convergentes entre si: enquanto em "Piá não sofre? Sofre" (I926, I934, I943, I944), Paulino forma parte da paisagem social da periferia paulista - das vidas marginalizadas, dos imigrantes, dos operários e das prostitutas - em "Tempo da camisolinha" (I939-I943), a criança aparece através de uma estrutura de ficção autobiográ- 
fica, como objeto autorreferente do eu que rememora a iniciação traumática no âmbito de uma família da próspera burguesia paulista. Porém é em Amar, verbo intransitivo (I927-I944) onde a cena de infância ou adolescência adquire, de modo ainda mais premente, o caráter de uma "política da estética": o texto transforma o enredo banal da iniciação sexual do filho de uma família burguesa em uma revelação paródica das hierarquias culturais, sociais e raciais e dos mecanismos de exclusão no interior da sociedade brasileira.

Amar, verbo intransitivo, ao mesmo tempo sátira psicológica e "idílio" experimental, ocupa um lugar de destaque dentro da prosa de Mário de Andrade que realiza uma pintura sarcástica da família burguesa. O texto tem um narrador cujo tom é o de um investigador interessado na sociologia e na psicologia brasileiras, que interpreta os acontecimentos e os personagens, ainda que com um resultado digressivo, ambivalente e metafórico. O texto incorpora o "material" linguístico brasileiro, como diz Mário de Andrade no "Posfácio", não com um propósito realista ou referencial, e sim "num sentido translato, metafórico": "A apropriação subconsciente das palavras para que elas tenham realmente uma função expressiva e caracteristicamente nacional" (Andrade, 2008a: I5I). Como no método psicanalítico freudiano, a língua coloquial falada funciona como uma revelação do subconsciente nacional, com suas fantasias, seus atos falhos, seus "lugares-comuns modismos brasileiros expressionais" (Andrade, 2008a: I53).

Se, como argumentou a crítica, a forma experimental do "idílio", em cenas que não se estruturam em capítulos nem respeitam uma hierarquia mais além do fragmento, segue modelos expressionistas (Lopez, 2008a: I62), , ${ }^{\text {I7 }}$ também o liga ao expressionismo o trabalho com o subconsciente brasileiro a partir do vocabulário tanto urbano quanto rural - "erros diários de conversação, idiotismos brasileiros e sobretudo psicologia brasileira" (Moraes, 200 I: I37) -, o interesse no folclore, o uso não referencial da linguagem, a perspectiva subjetivista e a paródica reavaliação da psicanálise. Mais além das referências explícitas a esse estilo ao longo do texto, a estética expressionista determina seu caráter de literatura falida, passageira, voltada para o presente - segundo diz Mário de Andrade em carta a Manuel Bandeira (Moraes, 200I: I37). Trata-se de um texto intransitivo, no sentido de uma ruptura com as regras da gramática e das leis da representação, como indica o título e como foi elaborado por Jacques Rancière:

A literatura ou a pintura intransitivas significam, antes de mais nada, uma forma de literatura ou de pintura que se libertou de sistemas de expressão que tornam um tipo particular de linguagem, um tipo particular de composição, ou possivelmente um tipo particular de cor apropriados para a nobreza ou banalidade de um tema específico [...] Na literatura, isso começou com a ideia de que não era necessário adotar um estilo particular para escrever sobre nobres, burgueses, camponeses, príncipes ou valetes. A igualdade dos temas e a indiferença relativa aos modos de expressão precede a possibilidade de abandono de qualquer tema em prol da abstração (Rancière, 2006: 53-54, tradução minha). 
Como texto intransitivo, Amar se libera das hierarquias da representação que fazem corresponder a banalidade ou a nobreza de certos temas a determinados estilos de expressão e põe uma temática banal em pé de igualdade com um estilo radicalmente experimental. Dita, assim, um regime de indiferença nos temas que se orienta, inclusive à abstração. O foco microscópico na vulgaridade dos costumes, na psicologia e na fisiologia da família paulista, os Sousa Costa, se conjuga assim com uma linguagem densamente experimental, oral, subconsciente e antirrealista. Assim, Carlos Sousa Costa, o adolescente de I5 anos para cuja iniciação sexual se contrata a Fräulein Elza, a governanta alemã, é o epítome do "individuo normal", incapaz de modificar seu destino, pura sensação fisiológica, "ele não conseguirá ser mais do que uma simples reação fisiológica” (Andrade, I927):

Carlos não passa de um burguês chatíssimo do século passado. Ele é tradicional dentro da única cousa a que se resume até agora a cultura brasileira: educação e modos. Em parte enorme: má educação e maus modos. Carlos está entre nós pelo incomparavelmente mais numeroso que inda tem no Brasil de tradicionalismo "cultural" brasileiro burguês oitocentista. Ele não chega a manifestar o estado bio-psíquico do indivíduo que se pode chamar de moderno. Carlos é apenas uma apresentação, uma constatação da constância cultural brasileira. E se não dei solução é porque meus livros não sabem ser tese. Não se consegue tirar do Amar, verbo intransitivo mais que a constatação de uma infelicidade que independe dos homens (Andrade, I927: 9).

Como "constatação da constância cultural brasileira", Carlos revela o caráter insípido, vulgar, tradicional dos "modos" e da educação brasileira, sintoma do imobilismo da cultura brasileira geral. Carlos é um sujeito pré-moderno, incapaz de modificar sua realidade: a vacuidade do enredo e das ações do personagem - "todo o sucedido para o menino foi absolutamente inútil" -, unido ao estilo modernista experimental, reforçam o caráter intransitivo do texto, que põe em cena os indivíduos em sua imanência e vulgaridade.

Por outro lado, como adverte Mário de Andrade em um artigo de I927, a investigação da iniciação sexual de Carlos responde à sua leitura dos Três ensaios sobre a teoria da sexualidade (1905), de Sigmund Freud, em um experimento paródico com a linguagem freudiana:

O livro está gordo de freudismo, não tem dúvida. E é uma lástima os críticos terem acentuado isso, quando era uma coisa já estigmatizada por mim dentro do próprio livro. Agora o interessante seria estudar a maneira com que transformei em lirismo dramático a máquina fria de um racionalismo científico. Esse jogo estético assume então particular importância na página em que "inventei" o crescimento de Carlos, seguindo passo a passo a doutrina freudiana (Andrade, I927: 9). ${ }^{18}$ 
A exploração ao mesmo tempo literária e psicanalítica de Carlos funciona como uma sátira da concepção tragicamente cindida da subjetividade - tanto da psicanálise freudiana e seu discurso científico sobre o eu, como da autoanálise proustiana. O texto se refere ao freudismo como uma "criancinha", um bebê recém-nascido, incomodado e revolucionário da paz do lar - "mamava que nem as outras, berrava sonoramente e trocava os dias pelas noites para dormir" (Andrade, 2008a: 58) -, que revela a não concordância dos sujeitos consigo mesmos, seu caráter de "misturas incompletas, assustadoras incoerências" (Andrade, 2008a: 58), assim como seu "hermafroditismo anatômico" (Andrade, 2008a: 59). Isto se verifica no desenvolvimento sexual de Carlos, que aparece como "perverso polimorfo". Seguindo as observações de Freud nos Três ensaios, a sexualidade quase infantil de Carlos aparece inicialmente como não orientada a um único objeto sexual, nem condensada em uma única zona erógena: todas as partes de seu corpo têm igual propensão à erotogeneidade, está dominada pelo instinto da crueldade, é oral, canibal, sadomasoquista, exibicionista e anal (Freud, 2000: 58). Carlos brinca violentamente com suas irmãs pequenas, bate, empurra, aperta e incomoda, enquanto elas, por sua vez, o denunciam com grunhidos e o mordem até fazê-lo sangrar. Seguindo a doutrina de Freud, segundo a qual uma das fontes fundamentais do prazer infantil consiste na excitação mecânica e lúdica em que as crianças se balançam, vibram e são arremessadas violentamente, estimuladas pela velocidade, atividade muscular e disputas verbais (Freud, 2000: 66), na família Sousa Costa as crianças cantam e bailam constantemente, e entram em brigas físicas ou verbais. As meninas aparecem sob uma sexualidade histérica, marcada pela sedução passiva e pela debilidade, enquanto Carlos se atira pelas escadas como um filhote no cio:

- Mamãe! Mamãe! Olhe Carlos! O menino agarrara a irmã na boca do corredor. Brincalhão, bem disposto como sempre. E machucador. Porém não fazia de propósito, ia brincar e machucava. Cingia Maria Luísa com os braços fortes, empurravaa com o peito, cantarolando, bamboleando no picadinho. Ela se debatia, danando por se ver tão mais fraca. Empurrada, sacudida, revirada. "Tatu subiu no pau..." — Mamãe! Mamãe! Me largue, Carlos! Me laargue! Sacudida revirada, tiririca, socos.

—... "Lagarto lagartixa / Isso sim é que pode ser" (Andrade, 2008a: 22).

O efeito rítmico, onomatopéico do texto emula a oralidade infantil e caseira, das explosões corporais e emotivas das crianças. Trata-se de uma linguagem antirreferencial, cheia de gerúndios e particípios, de verbos físicos, de movimento e exclamações, que funciona por acumulação e repetição. A linguagem coloquial, plena de conotações sexuais, revela o subconsciente da família burguesa paulista e o coloca em relação com a cultura popular regional, através do vocabulário da fauna e flora brasileiras e das referências à música popular. ${ }^{19}$ Estas referências regionais e populares aparecem deformadas, trabalhadas de modo lúdico, despojadas de toda intenção realista, como formas onomatopéicas que revelam uma carga inconsciente: “- Tu, turututu! parente 
do tatu e do urubu, pronto! - Então se eu sou parente do tatu e do urubu, você é tatua misturada com urubua. [...] Mamãe, ahn... mamãe! — Que foi, Aldinha! - Ahn... Carlos me chamou de tatua misturada com urubua..." (Andrade, 2008a: 77). A transposição literária da língua falada e o uso deslocado, metafórico, da língua regional e popular buscam revelar, de modo satírico, as pulsões animais, selvagens, incivilizadas da família paulista.

Além disso, Carlos, epítome do brasileiro, aparece como um sujeito em muitos sentidos indefinido, como revela a seguinte "ficha pessoal": "Carlos Alberto Sousa Costa. Nacionalidade: Brasileiro. Estado Social: Solteiro. Idade: Quinze (I5) anos. Profissão: (um tracinho). Intenções: (um tracinho). Observações extraordinárias: (um tracinho) "REGISTRO DO AMOR SINCERO”" (Andrade, 2008a: 47). Apesar de ser um "amante sincero", Carlos não tem profissão, nem intenções, nem personalidade - no sentido em que Macunaíma é o "herói sem nenhum caráter" -, e se define exclusivamente pelo fato de amar, de um modo carente de qualquer proveito ou utilidade social:

\begin{abstract}
Se alguém bota a mão no ombro, retira o corpo instintivamente. Se uma das irmãs, irmãs nem tanto, camaradas, que Carlos não bate em mulheres, lhe dá a mão, aperta até machucar. Aliás não corresponde ao aperto de mãos de ninguém. Aos de alguma superioridade que estendem a mão pra ele, entrega dedos sem contato, inertes, retos, que não se curvam pra apertar. Paralisia infantil. Nunca! Paralisia de Carlos. E doença particular. Quero mostrar, com o caso de ombro e o da mão, que ele não goza (nem mesmo as percebe) com as pequenas e mais ou menos mascaradas sensualidades que entretêm as fomes amorosas de todos, da aurora ao se deitar (Andrade, 2008a: 48).
\end{abstract}

Em parte por sua juventude - sua sexualidade ainda não completamente desenvolvida -, mas também por sua própria personalidade, Carlos é esquivo, lábil, tímido ou excessivo em suas reações. Se furta ao contato masculino e adulto ou responde a ele com apatia e indolência. É completamente indiferente às ânsias e desejos comuns, às ambições do homem adulto, heterossexual, e não chega a afirmar sua personalidade social: "não corresponde ao aperto de mãos de ninguém". Sem um posicionamento social claro e sem os desejos que corresponderiam ao homem adulto, Carlos se consome em um amor intransitivo, quase ridículo, infantil em sua puerilidade. O paralelo, uma vez mais, é com Macunaíma, que, como assinalou Alfredo Bosi, tem "alguma coisa de visceralmente infantil, uma aura de espontaneidade polimorfa que parece situá-lo em um espaço aquém da consciência entendida como responsabilidade ou coesão moral" (Bosi, 2003: 202). Como Macunaíma, Carlos é um ser infantilizado, espontâneo, "polimorfo", sujeito que se consome em seu próprio desejo, incapaz de agência social.

É por isso que, inclusive quando já desenvolvido sexualmente, Carlos resiste à praticidade regulamentada do amor alemão, tal como o concebe Fräulein: "divaga", se detém, "ondula", tem "preferências brasileiras": "Criança 
ainda é desajeitado, embonecava nele o homem latino, vocês sabem: o homem das adivinhações" (Andrade, 2008a: I 24). Essa qualidade "brasileira" do amor de Carlos se alia com um elemento mítico, selvagem, subconsciente: "E a gente então, os brasileiros misturados... [...] Entretanto tantanam no fundo do mato... Negros pesados dançando o cateretê. Silêncio grosso de cheiros de cernes, folhas, flores, terra, carnes, queimados pelo sol. Olhos relampeando na escureza da noite sem sono. Então a imaginativa trabalha" (Andrade, 2008a: I 25). O substrato da cultura brasileira indígena e negra se reatualiza na sexualidade indisciplinada de Carlos, na qual "a latinidade se confunde com os índios songamongas e a negralhada relumeante" (Andrade, 2008a: I 26). Com sua sexualidade "divagante", "corrosiva", Carlos transgride o desenvolvimento sexual tal como traçado pela teoria freudiana. "Minha vingança é que Freud não pode ter sensações de tantãs no fundo do mato. Nem pode sentir índios pesados, com dinamismos de ritual, dentro das gâmbias. Aliás nem Fräulein. Por isso é que falando de Carlos fui poeta, inventei" (Andrade, 2008a: I 26). As danças, a sexualidade pulsional, o mito e o rito indígenas e afro-brasileiros provocam a ruptura da norma sexual europeia, revelando assim a duplicidade inerente ao imaginário cultural do Brasil em sua condição periférica.

Visto desde a perspectiva racista e hierárquica de Fräulein, esse caráter mestiço, que une o indígena e o negro com a herança portuguesa, é claramente uma marca de inferioridade: "Os negros são de raça inferior. Os índios também. Os portugueses também. [...] E então os brasileiros misturados? Também isso Fräulein não podia falar" (Andrade, 2008a: 38). Porém a mistura de raças define não apenas Carlos, mas também o gado bovino de que é proprietário Sousa Costa, motivando uma comparação que atravessa o texto. Carlos, diz o texto:

não é magro, desraçado, apenas isso. O que sucede com as raças muito apuradas? A carne é bem cotada no Mercado, por ser muito mais macia. Pra conservar tais excelências a Inglaterra proíbe a intromissão do boi zebu nas marombas dela. [...] Ora no Brasil entrou o boi zebu. Entra o durhan também, e já pasta o curraleiro e principalmente o caracu. Porém ainda não se apurou coisa que valha. Será falta de carnes nestes membros possantes? Nem tanto, os ossos é que ainda não diminuíram. Delírios da seleção! (Andrade, 2008a: 76).

A mescla de raças, tanto do gado quanto do homem brasileiro, determina a percepção da inferioridade econômica e cultural, sua condição vulgar, não seleta. Esta relação metafórica entre a reprodução do gado e a sexualidade do filho, ambas sob o potentado patriarcal e administrativo de Sousa Costa, é central no texto: está na base de seu foco intrafamiliar, intradoméstico, e é a causa da atenção quase obsessiva que os Sousa Costa dedicam à proteção e ao controle da sexualidade e saúde da prole.

Assim, quando Aldinha e Maria Luísa brincam "de família”, emulam a obsessão de seus pais pela saúde e o corpo de seus filhos. Isto se coloca em evidência quando Maria Luísa adoece de gripe: 
uma linda união familiar. Brasileira. Portanto registremos com largueza: estão consternados com a doença de Maria Luísa: Sousa Costa pai, dona Laura, Carlos, Laurita, Aldinha. Não: Fräulein também. E Tanaka e a criada de quarto. A cozinheira e o motorista. Nem assim o rol se completa. O próprio lar, paredes, janelas, vocês reparam como as luzes vivem menos impetuosas agora? as plantas, a comida. Consternação geral (Andrade, 2008a: Ior).

Nessa paródia do discurso familiar, não apenas os pais tomam parte no sofrimento dramático pela gripe da filha, mas também os outros filhos, os empregados e inclusive os objetos e elementos inanimados: todos participam humoristicamente do desespero pela saúde de Maria Luísa.

A família moderna como estrutura fechada e celular, segundo análise de Michel Foucault, se funda nesta verdadeira obsessão com o bem-estar dos filhos, na necessidade de vigiar o comportamento sexual e a saúde da prole:

O corpo da criança vigiada, cercada em seu berço, leito ou quarto por toda uma ronda de parentes, babás, serviçais, pedagogos e médicos, todos atentos às mínimas manifestações de seu sexo, constituiu, sobretudo a partir do século XVIII, outro "foco local" de poder-saber (Foucault, 1988: 94).

Além disso, como analisou Anne Laura Stoler para as sociedades coloniais e pós-coloniais, o controle e a vigilância do contato das crianças de famílias brancas com os outros de raça e classe fez parte de uma verdadeira "missão civilizadora", de custódia diante da possibilidade de degeneração, contaminação e contágio, maneira de assegurar uma linhagem saudável de descendência e de proteger a própria identidade social e racial (Stoler, I995: I44-I45). A contratação de Fräulein, portadora de símbolos de superioridade racial e cultural (“ela é tão instruída”, diz a mãe) (Andrade, 2008a: 62), para a iniciação sexual de Carlos, tem como objetivo, por um lado, reafirmar a autoridade patriarcal do pai - "Souza Costa é um excelente pai-de-família. Pater familias" (Andrade, 2008a: 97) - sobre a sexualidade do filho, que fica assim enclaustrada no lar e, por outro, responde a uma vontade profilática, de "prevenir os inexperientes da cilada das mãos rapaces. E evitar as doenças" (Andrade, 2008a: 37), isto é, de evitar o contato com a alteridade social e racial, com "as 'meretrizes' que chupam o sangue do corpo sadio. O sangue deve ser puro" (Andrade, 2008a: 38), afirma Fräulein.

Essa ameaça torna-se ainda mais premente em um espaço urbano em pleno processo de modernização, como é São Paulo naquelas décadas. Como diz o senhor Sousa Costa:

Você sabe: hoje esses mocinhos... é tão perigoso! Podem cair nas mãos de alguma exploradora! A cidade... é uma invasão de aventureiras agora! Como nunca teve! COMO NUNCA TEVE, Laura... Depois isso de principiar... é tão perigoso! Você compreende: uma pessoa especial evita muitas coisas. E viciadas! Não é só bebida, não! Hoje não tem mulher-da-vida que não seja eterômana, usam morfina... E os moços imitam! Depois as doenças!... Você vive na sua casa, não sabe... é um horror! Em pouco tempo Carlos estava sifilítico e outras coisas horríveis, um per- 
dido! É o que te digo, Laura, um perdido! Você compreende... meu dever é salvar o nosso filho... Por isso! Fräulein prepara o rapaz. E evitamos quem sabe? Até um desastre!... UM DESASTRE! (Andrade, 2008a: 54-55).

Em contraposição com a segurança do lar burguês, a cidade aparece como um espaço ameaçador, que foi "invadido" pelas alteridades culturais - os imigrantes estrangeiros, assim como os imigrantes internos (o texto menciona italianos, belgas, árabes, polacos, russos, mulatos e cafuzos [Andrade, 2008a: 8I]). A figura da amante viciada, "morfinômana", "eterômana", "cocainômana" que seduz o filho, o contagia de vícios e doenças e o transforma em um jogador e num "perdido", concretiza a ameaça latente na cidade: a degeneração, o vício, a doença, a corrupção moral, que comprometem a possibilidade da concretização de uma linhagem saudável de descendência.

Nesse ponto, é o próprio senhor Sousa Costa quem, uma vez mais, traça um paralelo entre a administração da sexualidade do filho e o gado de que é proprietário: "Ao menos eu salvava a minha responsabilidade. Depois não é barato, não! tratei Fräulein por oito contos! Sim senhora: oito contos, fora a mensalidade. Naturalmente não barateei. Mais caro que o Caxambu que me custou seis e já deu um lote de novilhas estupendas (Andrade, 2008a: 62). O "preço" que se paga pela iniciação sexual de Carlos é comparado com o preço do touro e sua rentabilidade, revelando a "responsabilidade" - isto é, a autoridade ao mesmo tempo econômica e moral - do patriarca na administração de ambos. No final, a própria Fräulein é expulsa seguindo essa lógica, dado que o pai decide reatualizar seu "direito de propriedade":

Sousa Costa queria muito bem o filho, é indiscutível, porém isso de amores escandalosos dentro da própria casa dele lhe repugnava bastante. Não é que repugnasse propriamente... fazia irritação. Está certo: irritava Sousa Costa. O filho era dele, lhe pertencia. Que se entregasse a uma outra e ele sabendo, teve ciúmes, confesso. Se sente como que corneado! Tal era a sensação inexplicável de Sousa Costa pai (Andrade, 2008a: 1 27).

O pai busca recuperar o controle da circulação dos corpos no interior do lar, da administração do filho e seu comportamento sexual. Assim, confunde autoridade patriarcal, a economia de recursos, a sexualidade e o amor filial. Fräulein passa de símbolo do prestígio cultural e racial a representar a invasão da tão temida alteridade no lar. E Carlos, como futuro homem brasileiro que, já iniciado ao mundo adulto e heterossexual, seguirá seu destino de formar uma família, revela a instituição familiar como máquina de exclusão de toda alteridade - de raça, de classe, de gênero.

De fato, se é verdade que o texto privilegia a representação do núcleo familiar burguês urbano, em uma digressão sobre a sociabilidade brasileira sobressai a seguinte descrição: “... já se conhece bem a fotografia: A mãe está sentada com a família menorzinha no colo. O pai de pé descansa protetoramente no ombro dela a mão honrada. Em torno se arranjam os barrigudinhos. 
A disposição pode variar, mas o conceito continua o mesmo. Vária disposição demonstra unicamente o progresso que nestes tempos de agora fizeram os fotógrafos norte-americanos" (Andrade, 2008a: 24). A fotografia da família burguesa, epítome da respeitabilidade e da honradez - mãe sentada, pai de pé, filhos ao redor - aparece deslocada pelo uso de um vocabulário regional, proveniente do Norte e do Nordeste, "a família menorzinha no colo" "os barrigudinhos", que denota a indigência, a falta de recursos de parte da população rural. O comentário sobre a reprodutibilidade da pose-padrão torna ainda mais pungente o efeito satírico, sugere que ambas se repetem e evoca o fantasma da exclusão social que se esconde por detrás da pretensão de respeitabilidade burguesa.

Através de sua investigação ao mesmo tempo estética, sociológica e psicológica da infância no personagem de Carlos - sua linguagem, suas pulsões sexuais, assim como as hierarquias sociais e raciais que regem a circulação de seu corpo -, Amar verbo intransitivo chama a atenção para o silenciado, excluído e reprimido pela cultura brasileira tradicional, com seu imobilismo, sua banalidade e seu terror endógeno ao contágio social. Funciona, assim, no sentido de uma "política da estética", que intervém na partilha do sensível, reconfigurando os modos de perceber e experimentar o social, e desloca o sentido mesmo da comunidade. 
Alejandra Josiowicz é mestre e doutora em Língua e Cultura Brasileira e Hispano-Americana pela Princeton University. Foi professora assistente na Rutgers University. Atualmente realiza pósdoutorado na Casa de Oswaldo Cruz (COC/Fiocruz) com bolsa PAPD da FAPERJ. Suas pesquisas situam-se na área da sociologia da cultura e do pensamento social, debruçando-se no tema da infância. Publicou recentemente, entre outros artigos, "Estética y política de la infancia en Mário de Andrade" (20I4) e "La escritora que mató a los peces. Escritura, género y mercado en Brasil (I967-I978): un estudio de la literatura infantil de Clarice Lispector" (2013). 


\section{NOTAS}

I Uso "cenas" em um sentido similar ao desenvolvido por Jacques Rancière: a cena inscreveria o evento estético em uma constelação variável de modos de percepção, afetos e modos de interpretação, e constituiria a comunidade sensível e intelectual que torna possível essas relações (Rancière, 20I3: II).

2 A infância, como estudos históricos e sociológicos já apontaram, é antes uma categoria sociocultural do que um estado biológico, que se constitui durante os séculos XVIII e XIX na Europa e nos Estados Unidos, a partir da emergência do Estado moderno, no momento em que se fortalecia o núcleo familiar burguês e se restringiam os laços familiares tradicionais de parentesco. Entre os estudos pioneiros, sobressai o de Philippe Ariès, Centuries of childhood: A social history of family life (1962).

3 O livro foi publicado com o titulo de Belazarte em I934. Em I944, Mário de Andrade prepara o último manuscrito corrigido, o qual deu origem à última edição de Os contos de Belazarte publicada em forma póstuma em ig47 (Marques, 2008: I9).

4 O expressionismo, primeira versão das vanguardas na música, literatura e artes alemãs, emergiu a partir de uma série de grupos de artistas da pré-guerra (Die Bleue Reiter e Die Brücke, dentre outros) e chegou até os anos $1920 \mathrm{com}$ as primeiras obras de Bertolt Brecht (Macey, 2002).

5 Para um estudo da recepção do expressionismo em Mário de Andrade, ver a tese de Rosângela Asche de Paula, O expressionismo na biblioteca de Mário de Andrade: da leitura à criação (2007).

6 Encontram-se no IEB/USP, Fundo Mário de Andrade. Em suas pesquisas do folclore infantil paulista, Florestan Fernandes retoma os estudos da cultura oral infantil de Mário de Andrade, considerados por ele modelos e predecessores de sua própria pesquisa, coincidindo em muitas de suas conclusões (Fernandes, 2004: 313).

7 Como observou Antonio Candido, o objetivo era "não apenas a rotinização da cultura, mas a tentativa consciente de arrancá-la dos grupos privilegiados para transformá-la em fator de humanização da maioria, através de instituições 
planejadas" (Candido, I985: I4). Para a bibliografia sobre o tema, ver Barbato Jr. (2004), Raffani (200I), Williams (200I) e Abdanur (I992).

8 Para estudos nessa direção, ver Barbato Jr. (2004), Miceli (2012) e Berriel (I990).

9 As crianças que participavam dos distintos âmbitos do Departamento de Cultura de São Paulo foram objeto de pesquisas sociológicas, etnográficas, higiênicas, médicas e nutricionais, publicadas na Revista do Arquivo Municipal entre I935 e I938.

Io Para a bibliografia sobre os Parques Infantis, ver França Abdanur (1994) e Goulart de Faria (2002).

I I Alguns trabalhos têm insistido no aspecto autoritário das políticas públicas do Departamento de Cultura que, segundo essa visão, buscavam integrar os imigrantes à nacionalidade e preparar aos operários para as novas formas de trabalho surgidas na industrialização (Raffani, 200I). Sem negar o caráter biopolítico das iniciativas, assim como seu propósito de integrar diferentes grupos sociais à nacionalidade, é importante ressaltar que, nas políticas analisadas, a construção cultural partiu de componentes heterogêneos - tradições eruditas e populares, urbanas, rurais e cosmopolitas, trazidas pelos imigrantes - e que as diferentes camadas sociais foram consideradas como portadoras de cultura e potenciais sujeitos de expressão estética.

I 2 Estabeleceu, ainda, que as crianças deveriam assinar com seus nomes, deixando clara a nacionalidade de seus pais e a sua idade, e que a instrutora deveria adicionar se se tratava de uma criança branca, negra ou mulata. É por isso que os desenhos, que constam no IEB/USP, têm no verso a legenda "foi respeitada a expressão da criança quando disse o que fez", junto com seu nome, idade, nacionalidade dos pais e descrição racial. Sobre o tema, ver Gobbi (2002: I87-I 88).

I3 Sobre o tema, ver Coutinho (2002).

I4 Também constam no IEB/USP, Fundo Mário de Andrade, as anotações de suas aulas sobre o desenvolvimento estético infantil.

I5 Mário de Andrade possuía em sua biblioteca a Monografia de las escuelas de pintura al aire libre (1926), de José Vascon- 
celos, que, também como Diretor do Departamento de Cultura, havia lançado um programa artístico para crianças proletárias.

I6 Professora e pioneira da arte-educação, Anita Malfatti colaborou com Andrade ilustrando o catálogo "Parques infantis" e providenciando desenhos de sua aula de artes para crianças.

I7 Sobre o tema, ver também Cruz (2012).

I8 Segundo Telê Ancona Lopes, em sua edição de I923 dos Três ensaios, de Freud, principalmente no capítulo 3, "As transformações da puberdade", haveria notas de estudo para a construção de Carlos Sousa Costa (Lopes, 2008: I73).

I9 A canção que Carlos canta faz referência a um samba de carnaval inspirado no folclore rural, famoso naqueles anos "Tatu subiu no pau / é mentira de mecê / lagarto ou lagartixa / isso sim que pode sê" (Cruz, 20I2: 45).

\section{REFERÊNCIAS BIBLIOGRÁFICAS}

Abdanur, Elizabeth França. (1994). Parques infantis de Mário de Andrade. Revista do Instituto de Estudos Brasileiros, 36, p. 263-270.

Abdanur, Elizabeth França. (I992). Os "ilustrados" e a política cultural em São Paulo: o Departamento de Cultura na gestão Mário de Andrade (I935-I938). Dissertação de Mestrado. Programa de Pós-graduação em História/Instituto de Filosofia e Ciências Humanas/Unicamp.

Andrade, Mário de. (2008a). Amar, verbo intransitivo. Rio de janeiro: Agir.

Andrade, Mário de. (2008b). Piá não sofre? Sofre. In: Os contos de Belazarte. Rio de Janeiro: Agir, p. 99-I I4.

Andrade, Mário de. (2003). Oswald de Andrade: Pau brasil, sans pareil, Paris, I925. In: Oswald de Andrade. Pau Brasil. São Paulo: Globo, p. 73-88.

Andrade, Mário de. (I995). Questões de arte. In: Schwartz, Jorge (org.). Vanguardas latino-americanas: polêmicas, manifestos e textos críticos. São Paulo: Edusp, p. 386.

Andrade, Mário de. (I976). Pintura infantil. In: Taxi e crônicas no Diário Nacional. São Paulo: Duas Cidades, p. 277-280. 
Andrade, Mário de. (I966). Depoimentos 2. São Paulo, Grêmio da Faculdade de Arquitetura e Urbanismo/Centro de Estudos Brasileiros, pp. 66-77.

Andrade, Mário de. (I936a). Uma entrevista com o Sr. Mário de Andrade. O Estado de S. Paulo, 2 I de fevereiro, p. 3.

Andrade, Mário de. (I936b). Dia de São Paulo. Revista do Arquivo Municipal, I9, jan., p. 271-274.

Andrade, Mário de. (1927). A propósito de Amar, verbo intransitivo. Uma carta de Mário de Andrade. Diário Nacional, 4 de dezembro, p. 9.

Antelo, Raúl. (I99I). Prefácio. In: Primeiro caderno do aluno de poesia Oswald de Andrade. São Paulo: Secretaria do Estado da Cultura de São Paulo, p. I-Io.

Ariès, Philippe. (I962). Centuries of childhood: A social history of family life. Nova York: Knopf.

Barbato Jr., Roberto. (2004). Missionários de uma utopia nacional-popular. Os intelectuais e o Departamento de Cultura de São Paulo. São Paulo: Annablume.

Berriel, Carlos. (org.). (I990). Mário de Andrade, hoje. São Paulo: Ensaio.

Bloch, Ernst et al. (2002). Aesthetics and politics. Nova York: Verso.

Bosi, Alfredo. (2003). Situação de Macunaíma. In: Céu, inferno. São Paulo: Duas Cidades, p. 227-242.

Bürger, Peter. (1984). Theory of the avant-garde. Minnesota: Minnesota University Press.

Campos, Haroldo de. (I98I). Prólogo. In: Oswald de Andrade. Obra escogida. Caracas: Ayacucho, p. 9-4I.

Candido, Antonio. (1985). Prefácio. In: Duarte, Paulo. Mário de Andrade por ele mesmo. São Paulo: Hucitec, p. I2-I7.

Carvalho, Marta Maria Chagas de. (I997). Quando a história da educação é a história da disciplina e da higienização das pessoas. In: Freitas, Marcos Cezar de (org.). História social da infância no Brasil. São Paulo: Cortez, p. 269-287.

Coutinho, Rejane Galvão. (2002). A coleção de desenhos infantis do Acervo Mário de Andrade. Dissertação de Mestrado. Escola de Comunicações e Arte/USP. 
Cruz, Benilton Lobato. (2012). Olhar, verbo expressionista. O expressionismo alemão no romance Amar, verbo intransitivo, de Mário de Andrade. Tese de Doutorado. Programa de Pós-Graduação em Teoria e História Literária/Instituto de Estudos da Linguagem/Unicamp.

Faria, Ana Lucia Goulart de. (2002). Educação pré-escolar e cultura. São Paulo: Cortez.

Fernandes, Florestan. (2004). Folclore e mudança social na cidade de São Paulo. São Paulo: Martins Fontes.

Foucault, Michel. (I988). A história da sexualidade I: a vontade de saber. I3.ed. Trad. Maria Thereza da Costa Albuquerque e J. A. Guillon Albuquerque. Rio de Janeiro: Graal.

Freud, Sigmund. (2000). Three essays on the theory of sexuality. Nova York: Basic Books.

Gobbi, Márcia. (2002). Mário de Andrade e os desenhos das crianças pequenas: olhares de "Turista aprendiz". In: Freitas, Marcos Cezar de (org.). Desigualdade social e diversidade cultural na infância e na juventude. São Paulo: Cortez, p. I75-205.

Guy, Donna. (I998). The Pan American Child Congresses, I9I6 to I942: Pan Americanism, child reform and the welfare state in Latin America. Journal of Family History, 23, p. 272-29I.

Lopez, Telê Porto Ancona. (2008). Um idílio no modernismo brasileiro. In: Andrade, Mário de. Amar, verbo intransitivo. Rio de Janeiro: Agir, p. I59-I74.

Lopez, Telê Porto Ancona. (I996). Arlequim e modernidade. In: Marioandradeando. São Paulo: Hucitec, p. 85-Ioo.

Lopes, Telê Porto Ancona. (I988). Mário de Andrade e o artefazer da criança. In: Mário de Andrade e a criança. São Paulo: MAC/USP, IEB/USP, s/p.

Macey, David. (2002). Dictionary of critical theory. Nova York: Penguin.

Marques, Aline Nogueira. (2008). Uma história que Belazarte não contou. In: Os contos de Belazarte, Rio de Janeiro: Agir, p. 9-24.

Mello e Souza, Gilda de. (I980). Vanguarda e nacionalismo na década de vinte. In: Exercícios de leitura. São Paulo: Duas Cidades, p. 249-278. 
Miceli, Sérgio. (20I2). Mário de Andrade: a invenção do moderno intelectual brasileiro. In: Vanguardas em retrocesso: ensaios de história social e intelectual do modernismo latino-americano. São Paulo: Companhia das Letras.

Moraes, Marcos Antonio de (org.). (200I). Correspondência Mário de Andrade \& Manuel Bandeira. São Paulo: Edusp.

Paula, Rosângela Asche de. (2007). O expressionismo na Biblioteca de Mário de Andrade: da leitura à criação. Tese de Doutorado. FFLCH/USP.

Raffani, Patrícia Tavares. (200I). Esculpindo a cultura na forma Brasil: o Departamento de Cultura de São Paulo (I935I938). São Paulo: Humanitas/FFLCH-USP.

Rancière, Jacques. (2013). Aisthesis: scenes from the aesthetic regime of art. Nova York: Verso.

Rancière, Jacques. (20I I). Política de la literatura. Buenos Aires: El Zorzal.

Rancière, Jacques. (2006). Interview for the English version. In: The politics of aesthetics: the distribution of the sensible. Nova York: Continuum, p. 47-66.

Rizzini, Irene. (2002). The child-saving movement in Brazil: Ideology in late nineteenth and early twentieth century. In: Hecht, Tobias (org.). Minor omissions: Children in Latin American history and society. Wisconsin: University of Wisconsin Press, p. I65-180.

Stoler, Ann Laura. (1995). Race and the education of desire: Foucault's history of sexuality and the colonial order of things. Durham: Duke University Press.

Williams, Daryle. (200I). Culture wars in Brazil: the first Vargas regime, I930-I945. Durham: Duke University Press. 
Palavras-chave

Infância;

Mário de Andrade;

Expressionismo;

Literatura;

Sociedade.

Keywords

Childhood;

Mário de Andrade;

Expressionism;

Literature;

Society.

\section{POR UMA POLÍTICA DA ESTÉTICA EM MÁRIO DE} ANDRADE: EXPRESSIONISMO E INFÂNCIA

\section{Resumo}

Este artigo propõe considerar a cena da infância em Mário de Andrade a partir de dois níveis ou esferas de atuação distintos: por um lado, em sua intervenção políticocultural e, por outro, em sua produção literária. Em ambos os níveis, examina-se uma política da estética: uma conjunção de preocupações sociais e raciais e reflexões estéticas em torno da infância. Em seus múltiplos níveis estético-políticos, a infância em Mário de Andrade revela a marca do excluído, reconfigura os modos de perceber o social, e se orienta à transformação das hierarquias estéticas e da representação.

\section{TOWARDS A POLITICS OF AESTHETICS IN MÁRIO DE} ANDRADE: EXPRESSIONISM AND CHILDHOOD

\section{Abstract}

This article considers the childhood scene in Mário de Andrade's work, focusing on two main levels or spheres of actualization: on the one hand, his politico-cultural interventions and, on the other, his literary production. For both levels, it examines a "politics of aesthetics" in Mário de Andrade: a combination of social and racial preoccupations and aesthetic reflections around childhood. Through its multiple aesthetical and political levels, childhood in Mário de Andrade's work reveals that which has been excluded, reconfiguring ways of perceiving social life and pointing towards the transformation of the hierarchies of representation. 